MURILLAS ESCUDERO, J.M., «La responsabilidad civil extracontractual por daños morales en la relación conyugal», REDUR I3, diciembre 20I5, págs. III-I27. ISSN I695-078X

\title{
LA RESPONSABILIDAD CIVIL EXTRACONTRACTUAL POR DAÑOS MORALES EN LA RELACIÓN CONYUGAL
}

\author{
Juan Manuel MURILLAS ESCUDERO \\ Profesor Contratado Doctor de Derecho Civil \\ UNIVERSIDAD DE LA RIOJA
}

SuMARIO: I. La infidelidad en el matrimonio. II. Infidelidad y ocultación de la verdadera paternidad biológica. III. Doctrina del Tribunal Supremo. IV. Jurisprudencia de Audiencias Provinciales. IV.I. Sentencias a favor del resarcimiento del daño moral. IV.2. Sentencias que desestiman el resarcimiento del daño moral. V. Conclusiones. VI. Referencia al daño moral en las relaciones paterno-filiales. VII. Bibliografía.

RESUMEN: Progresivamente se va abriendo paso en los tribunales la exigencia de responsabilidad civil por daños y perjuicios causados durante el matrimonio. Es una cuestión controvertida por el ámbito en el cual se aplica. Este trabajo tiene por objeto el análisis de la aplicación del art. I.902 CC en la infidelidad conyugal cuando ha existido una ocultación de la verdadera paternidad biológica del hijo o hijos durante el matrimonio, y brevemente en las relaciones paterno-filiales.

PALABRAS ClAVE: Infidelidad en el matrimonio, ocultación de la verdadera paternidad bilógica, daño moral, responsabilidad civil.

ABSTRACT: Demanding civil responsibility for damages in marriage is becoming more and more important in court. It is a controversial issue because of the context in which it is applied. The goal is the application of article I9O2 to marital infidelity when the child or children's true biological paternity has been concealed in marriage and in the parent-child relations.

KEY WORDS: marital infidelity, concealment of true biological paternity, moral damage, civil responsibility

\section{La infidelidad en el matrimonio}

Viene manifestando la doctrina el acercamiento a nuevas responsabilidades civiles por daños morales entre cónyuges, abandonando paulatinamente la inmunidad familiar y 
considerando la aplicación del Derecho de daños a un campo ajeno como es el Derecho de familia ${ }^{\mathrm{I}}$.

La reforma llevada a cabo en el CC por la Ley I5/2005 ha dejado sin contenido los arts. 82 y 87 y ha suprimido las causas que podían alegar los cónyuges para solicitar la separación o el divorcio. Esta modificación lleva implícita una evolución jurídica hacia formas más abiertas de concebir el matrimonio, y a la vez, pone de manifiesto la creciente debilidad del vínculo conyugal.

En el matrimonio el deber de guardarse fidelidad es un deber incoercible y lo asumen recíprocamente los cónyuges en el momento de contraer matrimonio afirmando su compromiso de cumplir el contenido del art. 68 CC. Sin embargo, suprimidas las causassanción que podían invocar los cónyuges para ejercitar la acción de separación o divorcio, la reflexión me lleva a determinar el alcance jurídico del deber-obligación de los cónyuges de guardarse fidelidad. Con la reforma llevada a cabo la obligación de los cónyuges de guardarse fidelidad parece quedar más como un deber de carácter ético y moral, que jurídico, porque los posibles daños que la infidelidad pudiera causar en el cónyuge que la sufre no tiene consecuencias jurídicas a la vista de la reforma legal. Si el legislador ha suprimido las sanciones jurídicas derivadas del incumplimiento de estos deberes que establecía el CC hasta la aprobación de la Ley 15/2005, la naturaleza jurídica de estos deberes queda bastante difuminada. Actualmente en la normativa civil no hay una norma específica que establezca una sanción jurídica delimitada al cónyuge que incumple el deber de fidelidad, más allá del contenido genérico del art. 855. $\mathrm{I}^{\circ} \mathrm{CC}$ respecto al incumplimiento grave o reiterado de los deberes conyugales.

El legislador cuando modifica el CC y suprime las causas para solicitar la separación o el divorcio, no establece una forma de resarcimiento del daño moral que la infidelidad haya podido causar al cónyuge fiel y cumplidor de su deber. La vulneración del deber de fidelidad puede llevar un reproche social pero no hay consecuencias jurídicas derivadas de su violación, en consecuencia la infidelidad en sí misma no da lugar al resarcimiento por daño moral.

Si admitiéramos la obligación de indemnizar el daño moral que puede causar la infidelidad estaríamos realizando una contrarreforma del CC volviendo a establecer una sanción por la infidelidad. ¿Dónde quedaría la autonomía privada de la Exposición de Motivos de la Ley 15/2005?² ¿Y cómo obligamos al cónyuge a mantener la exclusividad

${ }^{2}$ Ya en el año 2000 RoCA I TRÍAs, E., escribe «que producido un daño en las relaciones familiares y que no esté específicamente establecida una forma de resarcimiento, aunque difícil la aplicación del art. I.902 CC si el daño se produjera, pienso que nada nos impediría aplicar el principio de que quien causa daño paga, porque las relaciones familiares no son causa de impunidad». «La responsabilidad civil en el derecho de familia. Venturas y desventuras de los cónyuges, padres e hijos en el mundo de las responsabilidad civil», en Moreno MARTínEZ, J. A. (Coord.), Perfiles de la responsabilidad civil en el nuevo milenio, Madrid, Dykinson, 2000, pág. 562. FERRER RiBA, J.: «Relaciones familiares y límites del derecho de daños», InDret, (http://www.indret.com), octubre, 200I, pág. I5. LÓPEZ DE LA CRUZ, L.: «El resarcimiento del daño moral ocasionado por el incumplimiento de los deberes conyugales», InDret, octubre, 20IO, págs. 32-35. RodRíGUEZ GuiTIÁN, A. Ma.$:$ «De nuevo sobre la reparación de los daños en el ámbito del matrimonio (A propósito de la STS de I4 de julio de 2010)», Diario La Ley, 7582, 2OII, págs. 8-ir. FARnós Amorós, E.: «Remedios jurídicos ante la falsa atribución de la paternidad», Derecho Privado y Constitución, 25, 20II, págs..33-36. BARCELó DOMENECH, J.: «El criterio de imputación de la responsabilidad civil en el ámbito familiar», en Moreno MARTíneZ, J. A. (Coord.), La responsabilidad civil en las relaciones familiares, Madrid, Dykinson, 20I2, págs. II7 y ss.

${ }^{2}$ Que para explicar la posibilidad de disolver el matrimonio por la sola voluntad de uno de los cónyuges, y eliminando cualquier sentimiento de culpa señala «se estima que el respeto al libre desarrollo de la 
sexual? Lo importante es determinar la tutela jurídica de los deberes conyugales y sus remedios jurídicos en caso de violación de los mismos a través de las actuales normas del $\mathrm{CC}$, en las cuales encajarían la reparación del daño moral, pero la infidelidad no puede dar lugar a resarcir el daño causado.

La redacción actual de los arts. 8I y 86 CC ofrece tutela y remedio jurídico al cónyuge que haya sufrido la infidelidad del otro y no quiera seguir manteniendo el matrimonio, concurriendo los requisitos legales el cónyuge podrá ejercitar la acción de separación o divorcio y el Juez deberá estimar la petición solicitada de forma unilateral por uno de los cónyuges, aunque el otro se oponga a separarse o disolver el matrimonio. Por consiguiente la tutela jurídica y el remedio jurídico por haber violado un cónyuge el deberobligación conyugal de guardarse fidelidad ya tiene una respuesta legal en el CC . $^{3}$.

\section{Infidelidad y ocultación de la verdadera paternidad biológica}

Ahora bien, la actual reforma permite reflexionar si en determinadas situaciones especialmente graves vulnerando el deber de fidelidad es procedente aplicar el art. I.902 CC ajeno en las relaciones familiares, en las cuales los posibles incumplimientos de los deberes conyugales por cualquiera de los cónyuges tenían su cauce natural en las normas del Derecho de familia, que ofrecían una respuesta legal cuando la infidelidad era una de las causas de separación o divorcio.

En situaciones concretas la infidelidad puede originar unas consecuencias jurídicas derivadas del daño moral, y, en su caso, patrimonial, cuando esa infidelidad ha dado lugar a procrear la esposa con un tercero ocultando la verdadera paternidad biológica al marido. Bien teniendo conocimiento la esposa, o de forma accidental cuando crea haber utilizado los medios posibles para evitar el embarazo, o incluso, sin su conocimiento porque durante la concepción mantuvo relaciones sexuales con su marido y con un tercero y descubre a posteriori que el hijo no es de su marido. Sin embargo, por diferentes causas se descubre que la paternidad biológica no corresponde al marido, cuando éste estaba convencido que el hijo o hijos eran suyos. En este punto se debe estudiar si procede la aplicación de la responsabilidad civil del art. I.902 para el resarcimiento del daño moral causado al marido concurriendo dolo o culpa en la conducta de la esposa.

Que la reforma realizada en el CC conlleve un debilitamiento del vínculo conyugal no supone que cuando se hayan lesionado los sentimientos más nobles del cónyuge no haya lugar a ningún tipo de responsabilidad. El matrimonio hace tiempo que ha dejado atrás la desigualdad de los cónyuges, la jerarquía patriarcal, la sumisión de la esposa al marido, y son los principios de igualdad, libertad, intimidad, desarrollo de la personalidad dentro del matrimonio las raíces que constitucionalmente consagran las relaciones conyugales siendo ambos cónyuges portadores de los derechos fundamentales como individuos.

personalidad, garantizado en el artículo io.i de la CE, justifica reconocer mayor trascendencia a la voluntad de la persona cuando ya no desea seguir vinculada con su cónyuge».

3 Son numerosos los autores que consideran que el incumplimiento del deber de fidelidad no puede dar lugar al resarcimiento del daño, entre otros, FARNós AMORós, E.: «Indemnización del daño moral derivado de ocultar la paternidad», InDret, 2007, págs. I2 y 20. LÓPEZ DE LA CRUZ, L.: «El resarcimiento del daño moral...» cit., pág. 30. Rodríguez Guitián, A. Mª: «De nuevo sobre la reparación de los daños ...», cit., pág. I83I. 
La actual minoración de fuerza normativa del vínculo matrimonial unido al hecho de que los cónyuges no pueden reclamarse jurídica ni coactivamente la obligación de guardarse fidelidad, no debe impedir la aplicación del art. I.902 cuando se haya producido un incumplimiento de especial y relevante gravedad para la familia. Si durante el matrimonio la esposa ha incumplido el deber de fidelidad y las consecuencias salen a la luz durante el matrimonio o a raíz de una crisis matrimonial y se descubre la verdadera paternidad biológica del hijo o hijos del matrimonio que resultan no ser del marido, sino de un tercero, demostrado el daño moral y los demás requisitos para que surja la responsabilidad civil del art. I.902: acción u omisión culpable de la madre, existencia de daño moral, y finalmente imputación objetiva respecto a la madre, se derivan unas consecuencias jurídicas, pero no por incumplimiento de la obligación de guardarse fidelidad que tienen los cónyuges, sino por un hecho distinto: ocultamiento de la verdadera paternidad biológica del hijo.

También se debe considerar la posible responsabilidad patrimonial del tercero (padre biológico), si en connivencia con la madre era consciente de la situación y desearon ambos tener descendencia, bien con ánimo de perjudicar directamente al marido, (caso flagrante de dolo por parte de la esposa), o por deseo de la madre de quedarse embarazada ante la imposibilidad de lograrlo con su marido siendo el tercero consciente de la situación y de la relación extramatrimonial de la esposa.

\section{Doctrina del Tribunal Supremo}

Una aproximación al daño moral puede extraerse de las definiciones que ofrece el TS. La definición del daño moral que da la STS de 22-02-200I (RJ 2242), Ponente D. Luis Martínez-Calcerrada y Gómez, integra «(...) cualquier frustración, quebranto o ruptura en los sentimientos, lazos o afectos, por naturaleza o sangre que se den entre personas allegadas fundamentalmente por vínculos parentales, a consecuencia del hecho ilícito (...)». En una sentencia anterior de I4-I2-I996 (RJ 8970), Ponente D. Eduardo Fernández-Cid Temes, ya señaló lo que entiende por daños morales: «representan el impacto, quebranto o sufrimiento psíquico que ciertas conductas, actividades o, incluso, resultados pueden producir en la persona afectada y cuya reparación va dirigida a proporcionar en la medida de lo posible, una compensación a la aflicción causada, cuya determinación compete al juzgador de instancia».

Respecto al tema de la infidelidad con ocultación de la verdadera paternidad biológica del hijo, han sido cuatro las sentencias del TS de la Sala $\mathrm{I}^{\mathrm{a}}$ las que han tratado la materia: (SSTS. 22-07-I999 (RJ 572I), Ponente D. Alfonso Barcala Trillo-Figueroa, 30-07I999 (RJ 5726), Ponente D. Alfonso Barcal y Trillo Figueroa, I4-07-20I0 (RJ 5I52), Ponente D. Francisco Marín Castán, y I8-o6-20I2 (RJ 6849), Ponente D. José Antonio Seijas Quintana.

La doctrina emanada en estas sentencias sobre reclamación de daños morales por ocultación de la verdadera paternidad biológica, no ha aportado a las Audiencias una doctrina clara y coherente, aunque sí uniforme (rechazo de la pretensión) sobre la reparación económica del daño moral al cónyuge cuando ha mediado ocultación de la verdadera paternidad. El TS ha mostrado resistencia a pronunciarse de forma decidida a 
favor o en contra del resarcimiento de daños morales entre cónyuges, siendo reacio a la entrada del Derecho de daños en las relaciones conyugales.

En la primera sentencia que se pronuncia sobre reclamación de daños morales (entre otros) por ocultación de la verdadera paternidad biológica del hijo de 22 de julio de I999, (RJ I999/572I), Ponente D. José Menéndez Hernández, el demandante solicitaba a la madre el pago de 24.000 .000 de pesetas, incluidos los intereses de esta cantidad durante I5 años correspondientes a los alimentos abonados por el actor a la demandada a favor del hijo, más 25.000.000 de pesetas por el daño moral sufrido por la actitud y comportamiento doloso de la esposa al ocultar la verdadera paternidad de aquél.

El TS desestima el recurso porque no aprecia comportamiento doloso en la esposa que le obligue a indemnizar. Argumenta que la madre desconocía la paternidad hasta la interposición de una acción de impugnación de la paternidad a instancia del propio hijo, bien que podían existir «posibilidades y sospechas pero no un conocimiento pleno y de total certidumbre».

Concluye: «Los supuestos que comportan la aplicación del art. I.902 del texto legal sustantivo, vienen a originar, como consecuencia de esta aplicación, una reparación por el daño causado, que puede hacerse extensiva al doble ámbito patrimonial y moral, pero ello no resulta aplicable al caso de autos, en el que, como queda razonado, no era posible hacer aplicación del meritado precepto, debido a no haberse apreciado una conducta dolosa en el comportamiento de la señora C».

El núcleo del recurso de casación es determinar si ha existido mala fe de la esposa y como hay «sospechas» y no «certidumbres» considera que no ha quedado demostrado ese extremo y rechaza la aplicación del art. I.902, pero bien recuerda E. ROCA ${ }^{4}$ que el citado artículo no exige el dolo para el nacimiento de la obligación de indemnizar.

La segunda sentencia de 30 de julio de $1999^{5}$ (RJ I999/5726), Ponente D. Alfonso Barcala Trillo-Figueroa, se basa en unos hechos parecidos, -ocultación de la verdadera paternidad-, aunque diferentes, porque es la esposa la que impugna la paternidad de dos hijos del matrimonio después de haberse producido la separación matrimonial de mutuo acuerdo. Demostrada la paternidad biológica de un tercero, el esposo interpone una demanda reclamando a la esposa 22.200 .000 pesetas (I2.200.000 pesetas por el mantenimiento de los «dos hijos» durante su matrimonio y por la devolución de las cantidades entregadas durante el período de separación de hecho en concepto de pensión alimenticia a los que creía que eran sus hijos), y ı..000.000 de pesetas por daño moral padecido a consecuencia de la infidelidad de la demandada. El JPI $n^{\circ}$ 2I de Madrid dictó sentencia el 5 de octubre de 1992 estimando parcialmente la demanda y condenó a la demandada al pago de I0.000.000 de pesetas en concepto de daños morales, absolviéndole del resto de las peticiones formuladas contra ella. Recurre la sentencia la esposa y la AP, Secc. I0. ${ }^{a}$, el 28-II-I994 dicta sentencia revocando la referida resolución, absolviendo a la

\footnotetext{
${ }^{4}$ RoCA I TRÍAs, E.: «La responsabilidad civil en el Derecho de familia. Venturas y...», cit., pág. 56I.

${ }^{5}$ Comentada por Ragel SÁnCheZ, L. F.: en «Comentario a la sentencia del Tribunal Supremo de 30 de julio de I999», CCJC, 52, 2000, págs. I53-163.
} 
demandada de todos los pedimentos de la demanda. Recurrida esta sentencia en casación el TS confirmó el fallo de la Audiencia.

El demandante fundamentó el recurso de casación denunciando como infringidos los arts. 67 y 68 CC en relación con el art. I.IoI, en consecuencia la violación del deber de fidelidad debiera comportar un resarcimiento económico y como este deber es inherente al contrato matrimonial debe aplicarse el art. I.ıoı, argumento que rechazó el tribunal.

El razonamiento del TS es bastante más preciso que en la sentencia anterior, y señala: «Indudablemente, el quebrantamiento de los deberes conyugales especificados en los arts. 67 y $68 \mathrm{CC}$, son merecedores de un innegable reproche ético-social, reproche que, tal vez, se acentúe más en aquellos supuestos que afecten al deber de mutua fidelidad, en los que, asimismo, es indudable que la única consecuencia jurídica que contempla nuestra legislación substantiva es la de estimar su ruptura como una de las causas de separación matrimonial en el art. 82, pero sin asignarle, en contra del infractor, efectos económicos, los que, de ningún modo es posible comprenderles dentro del caso de la pensión compensatoria ... e igualmente, no cabe comprender su exigibilidad dentro del precepto genérico del art. I.ıo , por más que se estimen contractuales estos deberes en razón de la propia naturaleza del matrimonio, pues lo contrario obligaría a estimar que cualquier causa de alteración de la convivencia matrimonial, obligaría a indemnizar».

Señala la sentencia que el incumplimiento del deber de fidelidad no constituye un supuesto de responsabilidad para el cónyuge infiel, la única consecuencia es la separación matrimonial. En la legislación actual no tiene consecuencias jurídicas, en su caso, la censura ético-social.

En esta sentencia el recurrente ejercita la acción del art. I.IoI CC, quizá a la vista de la sentencia anterior en un intento de eludir la demostración de la conducta dolosa de la esposa para que se estimaran sus pretensiones, en tanto y cuanto el art. I.Ior extiende la obligación de indemnizar por los daños y perjuicios causados en el cumplimiento de las obligaciones, no solo concurriendo dolo sino también negligencia, en este caso, en referencia al art. I.Ior la «obligación» de fidelidad, aunque se me hace difícil entender las razones que le llevaron al demandante a conferir a la obligación de fidelidad carácter contractual y ejercitara la acción en base al contrato matrimonial, cuando sabemos que el matrimonio con todas las reservas, es un negocio jurídico de Derecho de familia y el art. I.IOI se refiere a obligaciones contractuales ${ }^{6}$.

Respecto a la infidelidad de la esposa, al hilo de mi argumento anterior sobre la procedencia o improcedencia de efectos económicos, esta sentencia es anterior a la reforma operada en el CC en 2005 y en aquella sentencia de 30 jul. I999, el TS ya señaló que las consecuencias dañosas derivadas de la infidelidad del cónyuge no generan efectos económicos a favor del que la padece. Posteriormente tuvo ocasión de pronunciarse la SAP León, Secc. 2. ${ }^{a}$, Io nov. 2010, $(\mathrm{AC} \backslash 2010 \backslash 2 \mathrm{I} 20)$, Ponente D. Antonio Muñíz Díez, sobre un caso de infidelidad del marido e hizo suyos los fundamentos jurídicos de la sentencia del TS respecto a las consecuencias económicas derivadas de la infidelidad, y desestima el recurso

\footnotetext{
${ }^{6}$ Considera FARNós AMORÓs, E.: «El precio de ocultar la paternidad», InDret, mayo, 2005, pág. 5, que quizás el éxito de la acción hubiese radicado en invocar el art. I.902 CC para la reclamación de los daños derivados de ocultar la verdadera paternidad.
} 
de apelación presentado por la esposa reclamando daños morales por las infidelidades de su marido.

La tercera sentencia de I4 de julio de $2010^{7}$ (RJ 20I0/5I52), Ponente D. Francisco Marín Castán, plantea una reclamación por daño moral y patrimonial sufrido por el marido por el descubrimiento de la infidelidad de la esposa durante el matrimonio y la ocultación de la paternidad de la hija durante diecinueve años.

El ex marido interpone contra su ex esposa una demanda en virtud del art. I.902 reclamándole $300.000 €$ por el daño moral derivado de la «pérdida de la hija»; I00.000 $€$ por daños morales derivados de los daños físicos y secuelas psicológicas producidas por la separación matrimonial; roo.000 € por el daño moral derivado del deterioro de su fama y honor por el conocimiento de la infidelidad de su ex esposa y la pérdida del vínculo biológico respecto de su hija, y finalmente, I4.638 $€$ por el daño patrimonial y enriquecimiento injusto por haber criado, educado, y alimentado a una hija no siendo suya.

La sentencia del JPI $\mathrm{n}^{\circ} 2$ de Plasencia (Cáceres) desestimó la demanda por considerar prescrita la acción aplicando el art. I.968.2 ${ }^{\circ} \mathrm{CC}$ al haber transcurrido más de un año entre el conocimiento del daño por el demandante y la interposición de la demanda, entendiendo por tanto que la acción ejercitada se fundaba en el art. I.902 CC. Recurrida la sentencia la Audiencia la confirma SAP, Secc. I. ${ }^{a}$, de I3 de septiembre de 2006 (JUR\2006\258I34), Ponente D. Juan Francisco Bote Saavedra. Recurre en casación el demandante con un único motivo del recurso fundándolo en infracción del art. I.969 CC y de la jurisprudencia de la Sala, que en los casos de daños continuados o de producción sucesiva e ininterrumpida considera que el plazo de prescripción de la acción de responsabilidad civil extracontractual no comienza a correr hasta la producción del resultado definitivo, si no es posible distinguir etapas diferentes o hechos diferenciados.

El TS distingue entre daño continuado y daño duradero o permanente a efectos de aplicar o no la prescripción de la acción. No cuestiona la aplicación del art. I.968.2 señala: «aunque la jurisprudencia sobre daños continuados o de producción sucesiva e ininterrumpida declara que el plazo de prescripción no comienza a contar hasta la producción del definitivo resultado, también matiza que esto es así cuando no es posible fraccionar en etapas diferentes o hechos diferenciados la serie proseguida». En este caso califica la naturaleza del daño producido en el demandante de daño duradero ${ }^{8}$, en consecuencia el plazo de prescripción comienza a correr «desde que lo supo el agraviado», como dispone el art. I.968.2 ${ }^{\circ}$ que es el verdaderamente aplicado, considerando prescrita la acción ejercitada sin vulneración del art. I.969. La prescripción de la acción evitó un pronunciamiento sobre el fondo del asunto.

En la cuarta sentencia de I8 de junio de 2012 (RJ 20I2/6849), Ponente D. José Antonio Seijas Quintana, el actor plantea una reclamación de I99.039,36 € ejercitando la acción del art. I.902 CC frente a su ex esposa y el tercero por daño moral derivado de la

\footnotetext{
${ }^{7}$ Comentada por Rodríguez Guitián, A. Mª: «De nuevo sobre la reparación de los daños...», cit., págs. I-II.

${ }^{8}$ Distingue la STS 28-IO-2009 (RJ 58I7), Ponente D. Francisco Marín Castán, entre daño continuado y daño duradero, en este caso el daño duradero o permanente es aquel que se produce en un momento determinado por el comportamiento del demandado, pero persiste a lo largo del tiempo, con la posibilidad, incluso, de agravarse por factores ya del todo ajenos a la conducta del demandado.
} 
concepción de dos hijas extramatrimoniales. El TS confirma la sentencia de la Audiencia de Guipúzcoa declarando prescrita la acción ejercitada. No entra al fondo del asunto.

En las cuatro sentencias dictadas hasta la fecha el TS se ha mostrado reacio a pronunciarse de forma decidida a favor o en contra del resarcimiento de daños morales entre cónyuges cuando se le ha planteado la pretensión económica por daños morales derivados de la ocultación de la verdadera paternidad biológica.

\section{Jurisprudencia de Audiencias Provinciales}

\section{IV.I. Sentencias a favor del resarcimiento del daño moral}

Hasta la fecha varias Audiencias se han pronunciado sobre los daños morales en el matrimonio por ocultación de la verdadera paternidad biológica, habiendo ejercitado el ex marido la acción del art. I.902 frente a su ex esposa, y en algún caso, también contra el tercero, padre biológico.

No hay una doctrina uniforme en ellas porque se encuentran con la dificultad que supone la ausencia de pronunciamientos del TS sobre el fondo del asunto, aunque se va abriendo paso en la jurisprudencia de las Audiencias la aplicación del art. I.902 para reparar los daños morales. En algunos casos también la obligación de resarcir los perjuicios patrimoniales causados al marido en el transcurso de la vida matrimonial, perjuicios derivados y a consecuencia del cumplimiento de las obligaciones paterno-filiales del «padre» con aquellos que creía sus hijos.

Hay un grupo de sentencias que exige el comportamiento doloso de la esposa para que surja la obligación de indemnizar al marido, sin embargo, en otras, basta el comportamiento culposo o negligente de la esposa. Entre las primeras, exigencia de dolo para estimar la demanda y la indemnización:

Antes de la reforma del CC por la Ley 15/2005, la SAP Valencia, 2 Nov. 2004, Secc. 7. ${ }^{a},(\mathrm{AC} \backslash 2004 \backslash 1994)$, Ponente Da María del Carmen Escrig Orenga. Tres de los cuatro hijos del matrimonio nacen de una relación extramatrimonial. Hace la Sala un pormenorizado estudio del recurso destacando varios aspectos importantes:

I. Respecto a la infidelidad conyugal acoge la doctrina emanada de la sentencia del TS de 30 de julio en la que se especifica que «el daño moral generado en uno de los cónyuges por la infidelidad del otro no es susceptible de reparación económica alguna, y que la única consecuencia jurídica que contempla nuestra legislación es la de ruptura del vínculo conyugal».

2. Respecto a la procreación de los hijos con el tercero señala, «la negligencia de los demandados en sus relaciones íntimas» que identificó con la falta de adopción de métodos anticonceptivos seguros. No podemos soslayar en este sentido que tuvo tres hijos en cuatro años. Entiende la Sala que existe dolo en el comportamiento de los demandados ocultando la verdadera paternidad a pesar de manifestar la esposa que la relación con el padre de sus hijos extramatrimoniales era una relación pasional, puntual e irregular y como mantenía relaciones sexuales con ambos creía que los hijos eran del marido. A esta conducta dolosa sería aplicable el art. I.902 a sensu contrario del argumento de la STS de 22 jul. I999, que señaló que hubiese sido aplicado el art. I.902 si se hubiese demostrado un comportamiento 
doloso de la esposa. En este caso concluye la Audiencia que se trata de un hecho generador de responsabilidad extracontractual y que obliga a reparar el daño causado.

La Audiencia otorgó una indemnización al ex marido de ı००.০०० € por los daños morales que deberán satisfacer solidariamente la esposa y su compañero, padre biológico de los tres hijos por ocultar de forma dolosa la verdadera paternidad.

La consideración de las siguientes sentencias están dictadas después de la aprobación de la Ley I5/2005.

SAP León, Secc. I. ${ }^{a}, 30$ Ene. 2009 (JUR \2009\I9243I), Ponente D. Fernando Javier Sanz Llorente. Confirma la sentencia dictada por el JPI. Concede una indemnización de $30.000 €$ al marido por los daños morales. Sintetizando los hechos: una mujer casada quiere ser madre y no lo consigue con su marido. Inicia una relación con un tercero con el fin de quedarse embarazada. Teniendo certeza del embarazo opta por mantener esporádicos encuentros sexuales con su marido para evitar sospechas de éste sobre el embarazo. El comportamiento doloso de la esposa lo fundamenta la Sala señalando: «urdió toda la estrategia referida con la finalidad de obtener su ansiada maternidad fuera del matrimonio, ya que con su esposo lo veía inviable, y sin tener en cuenta ni los sentimientos de su esposo ni el daño irreparable que su conducta produciría (...) mantuvo en secreto tal circunstancia haciendo creer a su esposo que la hija era suya». La esposa mantuvo de forma continuada la verdadera filiación de la menor sabiendo con certeza que la paternidad no correspondía a su marido.

SAP Murcia, Secc. 5. ${ }^{a}$ I 8 Nov. 2009 (AC $\left.\backslash 2010 \mid 60\right)$, Ponente D. José Manuel Nicolás Manzanares. Confirma la sentencia dictada por el JPI. Considera comportamiento doloso de los demandados (esposa y tercero) ocultando la verdadera paternidad, condenando solidariamente a la madre y al padre biológico a la indemnización concedida por el JPI: I5.000 € por los daños morales y i6.692,7I $€$ por daños patrimoniales por los alimentos abonados desde la sentencia de separación, estos últimos a cargo de la madre, fundamento jurídico: se trata de una simple aplicación de las reglas del cobro de lo indebido, algo que la esposa no tenía derecho a cobrar y que por error le ha sido indebidamente pagado, art. I.895 CC.

SAP León, Secc. 2. ${ }^{\text {a }} 2$ Ene. 2007 (JUR $\backslash 2007 \backslash 59972$ ), Ponente D. Alberto Francisco Álvarez Rodríguez. Concede una indemnización de $30.000 €$ por los daños morales a cargo de la madre y del padre biológico. Mantiene que el engaño de la esposa ocultando la verdadera paternidad es un comportamiento doloso objeto de responsabilidad civil. La esposa manifestó en el juicio que sabía que la menor era hija de su nuevo compañero desde el mismo momento que supo que estaba embarazada. En esta sentencia la Audiencia al igual que en la SAP de Valencia de 2 Nov. 2004, condena solidariamente por daños morales a la madre y al padre biológico, y además, condena a éste al pago de i6.200 € por las cantidades abonadas por el actor en concepto de alimentos a razón de $150 €$ al mes durante nueve años, el tiempo que medió desde el nacimiento de la menor y el momento que dejó de convivir con el actor y pasó a hacerlo en compañía de su madre y padre biológico tras la firmeza de la sentencia de impugnación de la filiación. 
SAP Valencia, Secc. 7. ${ }^{a}, 5$ Sept. 2007 (JUR $\left.\backslash 2007 \backslash 340366\right)^{9}$, Ponente D Pilar Cerdán Villalba. La Audiencia estima comportamiento doloso de la esposa por ocultar la verdadera paternidad. El marido descubre la no paternidad del hijo constante el matrimonio. La Sala rebaja la indemnización que concedió el JPI de ı०0.000 a I2.000 € por el breve período de tiempo de convivencia del marido con el que creía su hijo, escasamente un año después del nacimiento. Esta indemnización es por los daños morales causados al marido por la procreación con un tercero, no por la infracción del deber de fidelidad, señalando expresamente que «la jurisprudencia del TS es unánime en la no concesión de indemnización alguna derivada de la infidelidad conyugal ni por vía del Art. I.902 ni del Art. I.IOI CC».

Las sentencias siguientes admiten el comportamiento culposo de la esposa como causa para otorgar la indemnización.

SAP Alicante, Secc. 6. ${ }^{a}$, I6 Ene. 2013 (JUR \2013\150976), Ponente D. José María Rives Seva. La Audiencia confirma la sentencia del JPI estimando parcialmente la demanda interpuesta por el marido contra su esposa ejercitando la acción de responsabilidad civil del art. I.902 por daño moral por haber ocultado la esposa durante el matrimonio la verdadera paternidad biológica de la hija. La Sala condena a la esposa a indemnizar al marido en la cantidad de $25.000 €$ por el daño moral. Sin embargo la sentencia absuelve al tercero (padre biológico), con un curioso razonamiento «... existieron relaciones extramatrimoniales, pero las mismas no pueden originar por sí daños y perjuicios, sino a lo sumo ser causa de separación o divorcio, no pudiendo pretender el actor que el codemandado le anunciara aquellas relaciones habidas con su esposa constante el matrimonio, por ello la condena solamente puede ser de la esposa demandada y en este ámbito de la culpa o negligencia».

SAP Cádiz, Secc. 2. ${ }^{a}, 3$ abr. 2008 (JUR \2008\234675), Ponente D. Antonio Marín Fernández. Entiende la Sala que «(...) el mero incumplimiento del deber de fidelidad cualificado por el embarazo de un tercero atribuido falsamente por vía de presunción a su marido, es hecho que por sí mismo genera su responsabilidad civil». La demandada, pese a la crisis de la relación matrimonial seguía manteniendo relaciones sexuales con su marido y simultáneamente con el que resultó ser padre de su hijo. En esta situación cuando se queda embarazada sabe o puede saber que existe más de una paternidad posible. Señala la Audiencia que la esposa debió haber hecho desde el nacimiento todo lo razonable para determinar la paternidad biológica evitando así que se considere padre al marido por el juego de la presunción legal de paternidad matrimonial. «Esa conducta ya es en sí misma gravemente negligente y legitima su responsabilidad». Hace referencia a la SAP Barcelona, Secc. I8. ${ }^{a}$, I6 ene. 2007 (JUR $\backslash 2007 \backslash 323682$ ), señala que el argumento jurídico de esta sentencia se adecúa mejor a la realidad de las cosas, en consecuencia, el art. I.902 establece que cualquier hecho dañoso, antijurídico, imputable a una falta de diligencia de quien lo comete ya genera responsabilidad. Exigir en este ámbito una culpabilidad reforzada se antoja innecesario y además resulta, la mayoría de las veces imposible.

Concede una indemnización de $30.000 €$ por los daños morales. También admite daños patrimoniales por los alimentos abonados tras la sentencia de separación consistentes en I.050 € que deben ser restituidos por las reglas del cobro de lo indebido, art. I. 895 CC.

\footnotetext{
${ }^{9}$ Comentada por FARNós AMORÓs, E.: «El precio de ocultar la paternidad», cit., págs. I-II.
} 
SAP Barcelona, Secc.I8. ${ }^{a}$, I6 Ene. 2007 (JUR\2007\323682), Ponente Da María Dolores Viñas Maestre. El JPI ${ }^{\circ}$ I 8 dictó sentencia denegando al marido la indemnización por daño moral porque entiende que la conducta de la demandada no puede ser calificada de dolosa. Estima la Audiencia que efectivamente no se está ante un caso de dolo pero sí de culpa grave de la demandada que unida a la producción del daño da derecho a indemnización y justifican la aplicación del art. I.902. Considera negligente la actitud de la esposa que omite adoptar las medidas oportunas dirigidas a determinar la paternidad biológica porque pudo y debió sospechar que el padre de la menor podría ser otro distinto a su marido, porque la esposa había mantenido relaciones sexuales simultáneas con el marido y un tercero, y además, durante los primeros años de su matrimonio se había sometido a un tratamiento de fertilidad sin haberse quedado embarazada. Concluye la Audiencia: «(...) la culpa o negligencia a que se refiere el art. I.902 CC constituye un concepto más amplio que el dolo o intención maliciosa, de su actuación se deriva responsabilidad extracontractual».

Fija a favor del actor una indemnización de $15.000 €$ en concepto de daños morales, no sin antes hacer una referencia en torno a la existencia del daño moral y los elementos que lo integran citando la STS 22 feb. 200I (RJ 2242), Ponente D. Luis Martínez-Calcerrada Gómez, y respecto a su valoración las SSTS de I9-I2-I949 (RJ I463), 22-04-I983 (RJ 2II8), Ponente D. José Luis Albácar López, 25-6-I984 (RJ II45), Ponente D. Mariano MartínGranizo Gómez, 27-7-I994 (RJ 6787) Ponente D. Alfonso Villagómez Rodil, y 03-II-I995 (RJ 8353), Ponente D. Luis Martínez- Calcerrada Gómez, entre otras.

\section{IV.2. Sentencias que desestiman el resarcimiento del daño moral}

SAP León, Secc. 2. ${ }^{\mathrm{a}}, 23$ nov. $20 \mathrm{I2}$ (AC $\backslash 20 \mathrm{I2} \backslash \mathrm{I} 643$ ), Ponente D. Alberto Francisco Álvarez Rodríguez. En el JPI de Villablino se vio la demanda presentada por el marido contra su esposa, reclamando entre otras peticiones, I00.000 € por daño moral por ocultar la esposa la verdadera paternidad biológica del hijo, y una indemnización de $15.000 €$ por el daño patrimonial que le supuso haber abonado la pensión alimenticia de su «hijo» durante varios años. El Juzgado desestimó ambas pretensiones por ausencia de dolo en la esposa. La Audiencia confirma la sentencia. Sus argumentos jurídicos los basa en la SAP León, Secc. 2. ${ }^{a}$, Io nov. 2010, que a su vez hizo suyos los fundamentos jurídicos de la STS de 30-07I999 respecto a la ausencia de consecuencias económicas derivadas de la infidelidad. Y el argumento jurídico para rechazar la aplicación del art. I.902 por daño moral la STS de 2207-I999. No aprecia comportamiento doloso en la esposa: «(...) la demandada, que podía haber sostenido su desconocimiento de que su marido no fuera el padre de su hijo, en todo momento ha afirmado que su segundo hijo se engendró durante una crisis matrimonial en la que cada uno, con el conocimiento del otro, hacía su vida, que se encontraba ya embarazada cuando se produjo la reconciliación y que el marido sabía que el hijo no era suyo». Al estimar la Sala ausencia de dolo en la esposa también rechaza la indemnización por el daño patrimonial que le supuso al marido haber abonado la pensión alimenticia de su hijo durante varios años.

SAP Cádiz, Secc. 5· ${ }^{2}$, 2I sept. 20I2, (JUR \20I2\353634), Ponente D. Ramón Romero Navarro. El JPI $n^{\circ} 2$ de Rota desestima la demanda interpuesta por el marido por haber prescrito la acción ejercida del I.902 por la infidelidad conyugal y el ocultamiento de la verdadera paternidad. 
En el recurso ante la Audiencia el apelante invoca el incumplimiento contractual desarrollando la tesis contractual del matrimonio para solicitar la revocación de la sentencia. La Sala estima que se está ante un supuesto de responsabilidad civil extracontractual por los daños que como consecuencia de la infidelidad de la esposa se han producido y rechaza el argumento de la tesis mantenida por el actor en el recurso. Señala que el único motivo a estudiar es determinar si se ha producido la prescripción de la acción prevista en el art. I.902 CC para reclamar por los distintos conceptos de la demanda. Argumenta su fundamento jurídico en la STS de I4-IO-20Io a efectos de considerar vigente o prescrita la acción atendiendo a la distinción entre daño continuado y daño duradero o permanente.

En este caso la Sala califica la naturaleza jurídica del daño como daño duradero lo que conlleva que cuando presenta la demanda había prescrito la acción del art. I.902 exigiendo una indemnización por daños y perjuicios. Declara prescrita la acción sin entrar al fondo del asunto, considerando que el plazo de ejercicio comenzará a correr «desde que lo supo el agraviado», art. I.968 $2^{\circ} \mathrm{CC}$.

SAP A Coruña, Secc. 3. ${ }^{a}, 8$ nov. 20IO, (AC\2010|2303), Ponente D. Juan Ángel Rodríguez Cardama. La sentencia del JPI $\mathrm{n}^{\circ} 4$ de A Coruña estima parcialmente la demanda interpuesta por el marido contra su esposa versando sobre la indemnización de daños morales, psicológicos y contra el honor y prestigio que se le habían causado por ocultación dolosa de la esposa de la verdadera paternidad biológica de la hija del matrimonio. La sentencia condena a la esposa a una indemnización de $25.000 €$ a favor de su marido, pero por daños morales, excluyendo los demás daños. La sentencia señala que aquélla actuó de forma negligente en la concepción, y dolosa en cuanto a la ocultación al marido de la verdadera paternidad de la hija.

La Audiencia admite que la esposa pudo haber actuado de forma negligente porque aunque no tenía certeza sobre quién fuera el padre biológico de su hija, pudo haber adoptado las medidas para su determinación puesto que había mantenido relaciones sexuales con otra persona, debió haber adoptado las medidas tendentes a su verdadera determinación, que consistirían en poner en conocimiento de su cónyuge esas dudas y practicarse en su momento las pruebas biológicas, conducta que «aunque encomiástica y responsable, cabe plantearse si sería exigible, por sus consecuencias, máxime de resultar una progenie matrimonial y ante semejante cuestión este Tribunal, no sin vacilación, se decanta por considerar no exigible, desde la base, se recuerda, de una situación de duda».

Niega la sentencia la existencia de dolo en la conducta de la esposa, porque la hija, siendo ya mayor de edad, no quiso someterse a la prueba biológica para determinar la verdadera paternidad, especialmente por el grado de deterioro en las relaciones afectivas que mantenía con el que creía su padre, circunstancia que entiende la Sala como una actitud de desapego y afecto hacia él. Ante estos razonamientos, -dudas en la actitud negligente o culposa de la esposa y ausencia de dolo-, la Audiencia estima el recurso y revoca la sentencia apelada.

SAP Castellón, Secc. 3. ${ }^{a}$, Io feb. 2009 (AC\2009\346), Ponente D. José Manuel Marco Cos. El JPI $n^{\circ} 2$ de Villarreal desestimó íntegramente la demanda presentada por el ex marido contra su ex esposa por la concepción de un hijo extramatrimonial invocando el art. I.902, solicitando: I50.000 € por daño moral ocasionado por la pérdida de un hijo, $50.000 €$ por daño moral producido por los daños físicos y secuelas, $2.950 €$ en concepto de 
daño patrimonial generado por el precio de la prueba de paternidad y $800 €$ por el mismo concepto de daño patrimonial causado por el pago de la pensión de alimentos para el sustento del que creía hijo suyo. La reclamación asciende a $203.750 €$.

El JPI desestimó íntegramente la demanda presentada absolviendo a la demandada de todas las pretensiones solicitadas.

La Audiencia señala que el amparo legal del I.902 requiere que, «aquél contra quien se dirige la pretensión sea responsable de una acción u omisión en la que haya intervenido culpa o negligencia y que, además, haya producido un perjuicio». En la demanda el actor reprocha a su ex esposa que la negligencia no se basa en la infidelidad, sino en que la demandada no evitara la concepción en el ámbito de sus relaciones extramatrimoniales, ocultando el carácter extramatrimonial del hijo. La concepción se produjo estando los cónyuges separados de hecho y en la posterior reconciliación matrimonial la esposa mostró las dudas al marido sobre la paternidad del hijo, eludiendo éste la prueba de paternidad biológica. Concluye la Audiencia que no hubo negligencia en la concepción extramatrimonial ni conducta dolosa o culposa. Confirma en todos sus extremos la sentencia apelada.

SAP Segovia, II dic. 2007 (JUR $\backslash 2008 \backslash \mathrm{I} 48 \mathrm{I} 38$ ), Ponente D. Francisco Salinero Román. El JPI $n^{\circ} 3$ niega la indemnización al marido por el daño moral cuando descubre que el que creía su hijo no lo es. La base de la demanda es la reclamación que el marido formula frente a su ex mujer ejercitando la acción del I.902, acusando a su esposa que ha procedido de mala fe y ocultando maliciosamente con una actitud dolosa que el hijo no era suyo.

Sorprende el razonamiento de la Audiencia cuando señala que el hecho de que la madre fuera infiel no equivale a que tuviese conocimiento de que el padre del niño no era su marido. Afirma que no se puede hacer equivalente al dolo el hecho de que la esposa hubiese tenido relaciones sexuales con otra persona, porque también las mantenía con su esposo en el tiempo de la concepción y nacimiento del hijo. La Audiencia confirma la sentencia.

\section{Conclusiones}

I. ${ }^{a}$ El Derecho de familia no es un sistema cerrado y completo con capacidad para resolver con sus propias reglas todos los conflictos planteados en las relaciones conyugales. No hay ningún precepto del CC que excluya la aplicación del art. I.902 para exigir la responsabilidad civil a cualquiera de los cónyuges cuando su actitud haya causado un daño moral al otro y concurran los presupuestos exigidos en este artículo.

2. ${ }^{a}$ Los tribunales mantienen la inmunidad de los cónyuges en el incumplimiento de los deberes conyugales. La infidelidad por sí sola no otorga un derecho de indemnización por el daño moral. Sin embargo, cuando la esposa haya mantenido relaciones sexuales con un tercero sin consentimiento/conocimiento del marido y haya concebido uno o más hijos extramatrimoniales ocultándole la verdadera paternidad biológica, concurriendo dolo o culpa grave, podrá ejercitar éste la acción del art. I.902 por el daño moral causado. No puede haber inmunidad en el seno de las relaciones conyugales cuando se reclamen daños morales derivados de la ocultación de la verdadera paternidad. 
$3 .^{a}$ No tiene la misma relevancia una reiteración en las relaciones sexuales con el tercero, que una relación esporádica y subsiguientes dudas en la esposa sobre la verdadera paternidad sobrevenida y posterior ocultamiento de esas sospechas al marido con el objeto de mantener y poner a salvo la unidad y estabilidad familiar, evitando causar un daño y unas consecuencias desastrosas para la familia. En este segundo caso no existe dolo y quizá tampoco culpa grave, incluso puede ocurrir que el marido se haya enterado de la infidelidad y carácter extramatrimonial del hijo por terceras personas, por este motivo se deberán ponderar las circunstancias concurrentes en cada caso.

$44^{2}$ Para la valoración de la cuantía del daño moral se deberá atender: a la gravedad de las secuelas físicas o psíquicas del demandante causadas por el descubrimiento de que no era el padre; el número de hijos extramatrimoniales, su edad, el tiempo que haya durado la convivencia con ellos, y finalmente, se debe considerar si es posible que pueda seguir manteniendo en el futuro una relación afectiva con el que creía hijo o hijos suyos.

$5{ }^{a}$ Los tribunales deberán tener en cuenta la posibilidad de que el marido tuviera conocimiento de la verdadera paternidad biológica del hijo o hijos durante el matrimonio. Si el tribunal tiene certeza que el marido conocía la falsa atribución de la paternidad durante el matrimonio, no procederá indemnización alguna por daño moral, (se presupone que no existía tal daño) porque con su actitud pasiva consentía la situación, y además, muy importante, se plantearía la caducidad de la acción de impugnación de la paternidad sin llegar el tribunal a entrar al fondo del asunto porque no se puede dejar la impugnación a su entera discrecionalidad ${ }^{\mathrm{T}}$.

6. ${ }^{a}$ Valorar si es posible demandar al tercero (padre biológico) por el daño moral. Entiendo que si el tercero tiene certeza y constancia de que el hijo es suyo, si esto se demuestra, el tercero también puede ser demandado. Desde luego se debe probar la conducta dolosa interviniendo engaño y acuerdo de ocultar la paternidad entre la madre y el tercero.

7. ${ }^{a}$ Respecto a los perjuicios patrimoniales el esposo puede reclamar al padre biológico las cantidades entregadas por la educación y alimentación de los «hijos» durante la vigencia del matrimonio. La acción a ejercitar sería el enriquecimiento injusto del padre biológico durante el tiempo que ha durado el engaño y el esposo creía que el hijo o los hijos eran suyos y cumplía con sus obligaciones paterno-filiales. También si separados o divorciados los cónyuges, el esposo o ex esposo entrega a la esposa o ex esposa cantidades de dinero en concepto de pensión de alimentos para la educación y demás gastos de los hijos y descubre posteriormente que no es el padre, puede formular frente a ella el reembolso de las cantidades entregadas por error, ejercitando la acción de cobro de lo indebido por las cantidades que ésta haya estado cobrando a favor del hijo o hijos que el marido creía suyos, art. I.895, y los intereses legales correspondientes, art. I.896 CC.

\section{Referencia al daño moral en las relaciones paterno-filiales}

En los casos de crisis matrimonial tras la ruptura de la convivencia las relaciones paterno-filiales deben continuar mediante la custodia compartida o bien, si se ha atribuido

${ }^{\text {Io } V i d . ~ B A R b e r ~ C A ́ R C A M o, ~ R .: ~ L a ~ f i l i a c i o ́ n ~ e n ~ E s p a n ̃ a . ~ U n a ~ v i s i o ́ n ~ c r i ́ t i c a, ~ P a m p l o n a, ~ T h o m s o n ~ R e u t e r s ~ A r a n z a d i, ~}$ 20I3, pág. 286. 
la custodia a un progenitor se establece a favor del otro en la forma determinada en la resolución judicial el correspondiente régimen de visitas. En este contexto también se está abriendo paso en los tribunales la aplicación del art. I.902 para el resarcimiento del daño moral causado al progenitor que se ha visto impedido de mantener la custodia que tenía atribuida, o incumple o dificulta las relaciones con los hijos que mediante el régimen de visitas tenía establecido a su favor el progenitor no custodio.

El único caso que hasta la fecha se ha pronunciado el TS en las relaciones paternofiliales a favor de la responsabilidad civil extracontractual es la STS de 30 junio 2009 (RJ $5490)^{\mathrm{II}}$, Ponente $\mathrm{D}^{\mathrm{a}}$ Encarnación Roca Trías. El tribunal otorga una indemnización de $60.000 €$ por daño moral al hombre que reconoció como propio al hijo de su compañera y no pudo ejercer la guarda y custodia del menor que tenía atribuida. La madre se trasladó con el hijo de siete años de edad a Estados Unidos a una sede de la Iglesia de la Cienciología privando al padre durante once años de la guarda y custodia que tenía atribuida.

Respecto a la jurisprudencia de las Audiencias he tenido conocimiento de la SAP Cádiz, Secc. 2.. 8 abril 2002 (AC\2002\IO64), Ponente D. Manuel de la Hera Oca, que confirma la sentencia dictada por el JPI. Entiende la Audiencia, previo estudio de los requisitos que deben concurrir en la aplicación del art. I.902, que las dificultades que la madre de la menor y su nuevo esposo interponen entre su padre biológico y ella para que se cumpla el régimen de visitas establecido en la sentencia causan al padre biológico un sufrimiento o padecimiento psíquico que tiene su encaje en el daño moral sufrido y considera que se debe indemnizar el daño moral producido estimando correctamente invocado el art. I.902 CC.

Frente a esta sentencia la SAP Barcelona, Secc. I4. ${ }^{a}$, 3I oct. 2008, (AC \2009\93), Ponente D. Francisco Javier Pereda Gámez, rechaza la indemnización de $150.000 €$ en concepto de daños morales por la pérdida de la relación paterno-filial. Resumidos los hechos son los siguientes: El marido consta como padre legal de la menor durante 5 años. A raíz de la separación matrimonial el marido venía disfrutando de un amplio régimen de visitas con la que creía su hija. Posteriormente la madre comunica a su marido que el padre biológico es su actual compañero. Dictada sentencia de filiación en 2005 se establece un régimen de visitas de cuatro horas al mes que fue finalmente revocado en apelación dejando sin efecto toda relación. La Audiencia no aprecia conducta dolosa de la esposa porque las dudas sobre la paternidad surgieron después de la crisis conyugal cuando se aprecian rasgos físicos en la menor del padre biológico. Concluye para resolver la petición de indemnización que «no está previsto en nuestro ordenamiento responsabilidad por pérdida de la relación paterno-filial derivada de una infidelidad para los casos de culpa o negligencia».

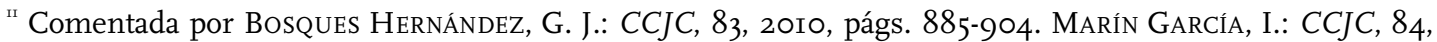
20I0, págs. I369-1390. Un comentario realizan también RUIZ JIMÉNEZ, J. y TEJEDOR MUÑOZ, L.: «Indemnización de los daños morales sufridos por uno de los progenitores al ser privado por el otro de relacionarse con su hijo», RCDI, 7I8, 20I0, págs. 805-8I3.
} 


\section{Bibliografía}

Algarra Prats, E., «Incumplimiento de deberes conyugales y responsabilidad civil», en MORENO MARTínEZ, J. A. (coord.), La responsabilidad civil en las relaciones familiares, Madrid, Dykinson, 20I2, págs. II-60.

Álvarez Olalla, Ma del P., «Prescripción de la acción ejercitada por el marido contra su ex mujer por los daños sufridos al determinarse judicialmente la filiación extramatrimonial», Aranzadi Civil-Mercantil, núm. 9, $201 \mathrm{I}$.

AtienZA NAVARro, $M^{a}$ L., «La incidencia de las reformas de 2005 en materia de efectos personales en el matrimonio», en DE VERDA y BeAmonTE. J. R. (coord.), Comentarios a las reformas de Derecho de familia de 2005, Pamplona, Thomson Aranzadi, 2006, págs. I49-I6I.

BARCELÓ DOMÉNECH, J., «El criterio de imputación de la responsabilidad civil en el ámbito familiar», en Moreno MartíneZ, J. A. (coord.) La responsabilidad civil en las relaciones familiares, Madrid, Dykinson, 2012, págs. 79-128.

Barber CÁrCAmo, R., La filiación en España. Una visión crítica, Pamplona, Thomson Aranzadi, 2013.

Bosques HernándeZ, G. J., «Comentario a la STS de 30 de junio de 2009», CCJC, núm. 83, 2010.

CArrasco Perera, A., «El precio de la infidelidad», Actualidad Jurídica Aranzadi, núm. 666/2005, (Tribuna), Pamplona, 2005.

COlÁs EsCANDÓN, A. Mª «nuevos daños indemnizables: las relaciones de familia», en HERRADOR GuARdia, M. J., (coord.), Derecho de daños, Las Rozas, Sepin, 20II, págs. 3I3-378.

De Verda y BeAmonte, J. R. y Chaparro MAtAmoros, P., «Responsabilidad civil por incumplimiento de los deberes conyugales», en DE VERDA Y BEAMONTE, J. R. (coord.), Responsabilidad Civil en el Ámbito de las Relaciones Familiares, Revista Aranzadi de Derecho Patrimonial, Thomson-Reuters Aranzadi, núm. 28, 20I2, págs. I03-I74.

DíEz-PiCAZo, L., El escándalo del daño moral, Cizur Menor, Thomson-Cívitas, 2008.

ElizAlde Redín, G., «¿Es indemnizable la infidelidad? », Revista Aranzadi Doctrinal, núm. 2/20II, Pamplona, 20II.

FARnós Amorós, E., «Remedios jurídicos ante la falsa atribución de la paternidad», Derecho Privado $Y$ Constitución, núm. 25, $201 \mathrm{II}$

- «Indemnización del daño moral derivado de ocultar la paternidad, (Comentario a la SAP de Barcelona, Secc. I8. ${ }^{a}$, de I6-oI-2007)», InDret, núm. 4, 2007.

— «El precio de ocultar la paternidad», (Comentario a la SAP de Valencia, Secc. 7. a, de 02-II-2004), InDret, núm. 2, 2005.

Fayos Gardó, A., «Daños morales en las relaciones familiares, Derecho de familia o de la responsabilidad civil», $A D C$, núm. 4, 201 I.

FERRER RibA, J., «Relaciones familiares y límites al Derecho de daños», InDret, octubre, 200I.

García Cantero, G., «Comentario a los arts. 67 y 68 del CC», en M. Albaladejo (Dir.) Comentarios al Código Civil y Compilaciones forales, t.: II, arts. 22 a I07 del CC., Madrid, Edersa, I986, págs. I84-I98.

LACRuz Berdejo, J. L., «Efectos del matrimonio», en LACRuz Berdejo, J. L. y OTROs: Elementos de

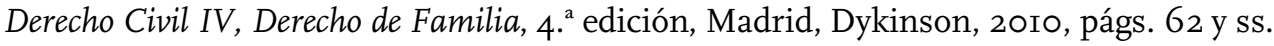

«Comentario al art. $68 \mathrm{CC}$ (revisado para la $2^{\text {a }}$ edición por J. RAMS AlBeSA y J. DELGADO ECHEVERríA), en AA.VV.: Matrimonio y divorcio. Comentarios al Título IV del Libro Primero del Código Civil, en J. L. LACRuz BerdejO. J. L. (Coord.), Madrid, Cívitas, I994, págs. 650-664.

LINACERO DE LA FUENTE, $\mathrm{M}^{\mathrm{a}}$, «Concepto y límites del daño moral: el retorno al pretium doloris», RCDI, núm. 720, 2010.

LÓPEZ DE LA CRUZ, L., «El resarcimiento del daño moral derivado del incumplimiento de los deberes conyugales», InDret, octubre, 20 Iо.

Marín GARCíA, I., «Comentario a la sentencia de 30 de junio de 2009», CCJC, núm. 84, 20 Io. 
Marín GaRCía DE LeONARDo, $\mathrm{M}^{a}$ T., «Separación y divorcio sin causa. Situación de los daños personales», RdP, núm. I6, 2006-I.

«Indemnización de daños y perjuicios por incumplimiento de deberes conyugales», en, Perspectivas del Derecho de familia en el siglo XXI, XIII Congreso Internacional de Derecho de familia, (CD), 2004, págs. I-23.

«Remedios indemnizatorios en el ámbito de las relaciones conyugales», en Daños en el Derecho de familia, De Verda y BeAmonTE, J. R. (coord.), Pamplona, Thomson-Aranzadi, 2006, págs. I47I77.

MARTín CASAls, M. y Ribot, J., «Daños en el Derecho de familia: un paso adelante, dos atrás», $A D C$, tomo LXIV, núm. 2, 2011 .

MARTíneZ CALCERRADA y GómEZ, L., «El daño moral: sus manifestaciones en el Derecho español», Diario La Ley, núm. 6996, 2008.

Novales AlquÉZAR $\mathrm{M}^{a}$ de A., «Hacia una teoría general de la responsabilidad civil en el Derecho de familia. El ámbito de las relaciones personales entre los cónyuges», RJN, núm. 60, 2006.

Paniza Fullana, A., «Filiación impugnada: Prescripción y daños continuados», Aranzadi Civil, 9, $20 I I$.

Ragel SÁnChez, L. F., «Comentario a la sentencia del Tribunal Supremo de 30 de julio de I999", CCJC, núm. 52, 2000.

Reglero CAMPos, L. F., «La prescripción de la acción de reclamación de daños» (Capítulo VIII), en L. Fernando Reglero Campos (coord.), Tratado de responsabilidad civil, Tomo-I, Parte general, $4^{a}$ edición, Pamplona, Thomson-Aranzadi, 2008, págs. I207-I345.

Ribot Igualada, J., «Nota crítica al libro coordinado por J. R. de Verda y Beamonte, Daños en el Derecho de familia, Pamplona, 2006» ADC, núm. LIX, 4, 2006.

ROCA I TRIAS, E., «La responsabilidad civil en el Derecho de familia. Venturas y desventuras de cónyuges, padres e hijos en el mundo de la responsabilidad civil», en J. A. Moreno MARTínez (coord.), Perfiles de la responsabilidad civil en el nuevo milenio, Madrid, Dykinson, 2000, págs. $53 \mathrm{I}-563$.

RodríGUEZ GuITIÁN, A. M $\mathrm{M}^{a}$, «De nuevo sobre la reparación de daños en el ámbito del matrimonio (A propósito de la STS de I4 de octubre de 20IO», La Ley, núm. 7582, 4 de marzo de 2011.

- «Función de la responsabilidad civil en determinadas relaciones de convivencia entre cónyuges y daños entre los miembros de la pareja de hecho», $R d P$, 2003-I.

Romero Coloma, A. $\mathrm{M}^{\mathrm{a}}$, «El deber de fidelidad conyugal y la responsabilidad civil por su infracción», La Ley, núm. 7646, 7 de junio de 2011.

Reclamaciones e indemnizaciones entre familiares en el marco de la responsabilidad civil, Barcelona, Bosch, 2009.

— «Indemnizaciones entre cónyuges y su problemática jurídica», RCDI, núm. 7I5, 2008.

SANCHO VilLaRREAL, L., «El deber de fidelidad conyugal como obligación jurídica y consecuencias de su infracción», $R d F$, núm. II, abril 200I.

VARGas Aravena, D., DAÑos CiVILES En EL MATRimonio, MADRID, LA LEY, 2009.

VIVAS TESÓN, I., «La responsabilidad aquiliana por daños endofamiliares», RDP, núm. 26, 20 II. 